\title{
Comunicação
}

[Communication]

\section{Frações dos compostos nitrogenados associados à parede celular em forragens tropicais}

\author{
[Fractions of cell wall nitrogenous compounds in tropical forages]
}

\author{
L.T. Henriques ${ }^{1,3}$, E. Detmann ${ }^{2,4 *}$, A.C. Queiroz ${ }^{2,4}$, S.C. Valadares Filho ${ }^{2,4}$, \\ M.I. Leão ${ }^{2}$, M.F. Paulino ${ }^{2,4}$ \\ ${ }^{1}$ Aluno de pós-doutorado - UFV, MG \\ ${ }^{2}$ Universidade Federal de Viçosa, \\ Av. P.H. Rolfs, s/n \\ 36571-000 - Viçosa, MG \\ ${ }^{3}$ Bolsista da CAPES \\ ${ }^{4}$ Bolsista do $\mathrm{CNPq}$
}

A avaliação da disponibilidade potencial dos compostos nitrogenados dos alimentos tem recebido atenção especial em condições tropicais em função da elevada associação destes à matriz orgânica da parede celular vegetal, associação essa que compromete a acessibilidade a estes compostos por parte dos microrganismos ruminais. Neste contexto, a fração dos compostos nitrogenados ligada à porção insolúvel em detergente ácido da parede celular (PIDA) tem sido empregada como preditor ou estimador do potencial de aproveitamento protéico nos alimentos por alguns dos principais sistemas nutricionais, como o sistema britânico (Agricultural..., 1993) e o sistema CNCPS (Sniffen et al., 1992), no sentido de, embora formada em parte por componentes aminoacídicos (Muscato et al., 1983), estes representariam a fração indisponível dos compostos nitrogenados aos microrganismos ruminais ou ao sistema enzimático intestinal (Sniffen et al., 1992).

Contudo, demonstrou-se em recentes estudos realizados em condições tropicais completa ausência de relação entre a fração dos compostos nitrogenados não degradável no ambiente ruminal e PIDA (Detmann et al., 2004) e a possibilidade de parte deste último ser digestível no intestino (Detmann et al., 2003). Dessa forma, a simples associação química do PIDA como preditor do potencial de aproveitamento dos compostos nitrogenados em alimentos, notadamente aqueles com elevados teores de componentes da parece celular, poderia ser considerada questionável em condições tropicais (Detmann et al., 2004).

Trabalhos que dimensionam as frações dos compostos nitrogenados ligados aos componentes da parede celular, associando a estas estimativas de seu potencial de degradação ruminal, são escassos em condições brasileiras. Assim, objetivou-se neste trabalho quantificar as frações totais e indegradáveis dos compostos nitrogenados associados aos componentes da parece celular de algumas forragens tropicais.

Foram utilizadas amostras de silagem de capimelefante (Pennisetum purpureum), silagem de milho (Zea mays) e cana-de-açúcar (Sacchararum sp.) coletadas em três repetições de campo, perfazendo o total de 9 amostras. Após a coleta, as amostras foram pré-secas em estufa de ventilação forçada $\left(60^{\circ} \mathrm{C} / 72\right.$ horas $)$ e moídas em moinho de facas com peneira de malha $1 \mathrm{~mm}$.

Recebido em setembro de 2006

Aceito em 21 de novembro de 2006

*Autor para correspondência (corresponding author)

E-mail: detmann@ufv.br

Apoio: CNPq, CAPES 
As amostras foram quantificadas quanto aos teores de matéria seca (MS), proteína bruta (PB), e cinzas, segundo métodos descritos por Official... (1990). As avaliações da fibra em detergente neutro (FDN), fibra em detergente neutro corrigida para cinzas e proteína (FDNcp), fibra em detergente ácido (FDA), fibra em detergente ácido corrigida para cinzas e proteína (FDAcp), compostos nitrogenados insolúveis em detergente neutro (PIDN), PIDA e lignina $\left(\mathrm{H}_{2} \mathrm{SO}_{4} \quad 72 \% \quad \mathrm{p} / \mathrm{p}\right)$ seguiram os protocolos descritos por Van Soest e Robertson (1985) e Licitra et al. (1996).

Os compostos nitrogenados da parede celular foram subdivididos em três diferentes subfrações: proteína associada à hemicelulose
(PHEM), proteína associada à celulose (PCEL) e proteína associada à lignina (PLIG). Os teores de PHEM foram estimados pela diferença entre PIDN e PIDA. Por sua vez, os teores de PLIG foram estimados diretamente sobre o resíduo das amostras após tratamento seqüencial em detergente ácido e ácido sulfúrico (Van Soest e Robertson, 1985), sendo os teores de PCEL estimados a partir da diferença entre PIDA e PLIG.

Todas as avaliações de compostos nitrogenados foram conduzidas por intermédio do método de Kjeldahl (Official..., 1990), utilizando-se o fator 6,25 para expressão dos teores como equivalentes protéicos. A composição química dos alimentos é demonstrada na Tab. 1.

Tabela 1. Composição química percentual dos alimentos, com base na matéria seca

\begin{tabular}{cccc}
\hline Item & Silagem de capim-elefante & Silagem de milho & Cana-de-açúcar \\
\hline MS $(\%)$ & 32,07 & 28,60 & 22,23 \\
Cinzas & 7,73 & 12,45 & 5,17 \\
PB & 4,82 & 5,78 & 2,60 \\
FDN & 75,72 & 58,62 & 46,75 \\
FDNcp & 70,04 & 52,69 & 43,07 \\
FDA & 51,98 & 33,57 & 28,09 \\
FDAcp & 43,57 & 27,32 & 25,74 \\
Lignina & 10,25 & 8,48 & 5,42 \\
\hline
\end{tabular}

MS- matéria seca; PB - proteína bruta; FDN - fibra em detergente neutro; FDNcp - fibra em detergente neutro corrigida para cinzas e proteína; FDA - fibra em detergente ácido; FDAcp - fibra em detergente ácido corrigida para cinzas e proteína.

Posteriormente, com o objetivo de se estimar a porção não degradável das diferentes frações dos compostos nitrogenados, as amostras foram submetidas a procedimento de incubação in situ por 240 horas (Detmann et al., 2004). Neste processo, triplicatas das amostras com aproximadamente $12 \mathrm{~g}$ foram acondicionadas em sacos de tecido não-tecido (TNT, $100 \mathrm{~g} / \mathrm{m}^{2}$ ) (Casali et al., 2005), mantendo-se a proporção de $25 \mathrm{mg} \mathrm{MS} / \mathrm{cm}^{2}$ de superfície, sendo incubadas no rúmen de um bovino alimentado com dieta contendo alimentos volumosos e concentrado, na proporção de 70:30, com base na matéria seca. Após 240 horas, os sacos foram retirados, lavados em água corrente até o total clareamento da água, e secos em estufa de ventilação forçada $\left(60^{\circ} \mathrm{C} / 72\right.$ horas $)$. Em seguida, o resíduo pós incubação foi submetido ao fracionamento dos compostos nitrogenados de forma similar ao material não-incubado.
As frações dos compostos nitrogenados foram apresentadas por intermédio de estatísticas descritivas. Por sua vez, a dimensão das frações indegradáveis dos compostos nitrogenados foram avaliadas por intermédio de análise de variância, segundo delineamento inteiramente casualizado, considerando-se três alimentos e três repetições. As médias foram comparadas por intermédio do teste DMS de Fisher $(\alpha=0,10)$.

As avaliações dos compostos nitrogenados associados a parede celular no alimento original estão descritas na Tab. 2. Verificou-se elevada participação de compostos nitrogenados associados à parede celular (PIDN) sobre o teor total de proteína bruta das diferentes forragens, $\mathrm{o}$ que concorda com outros resultados obtidos em condições tropicais (Cabral et al., 2000) e corrobora a importância quantitativa destes para a nutrição protéica de ruminantes manejados nos trópicos sob dietas com predomínio de alimentos volumosos. 
Tabela 2. Médias e erros-padrão da média para os teores de proteína insolúvel em detergente neutro (PIDN), proteína insolúvel em detergente ácido (PIDA), proteína associada à celulose (PCEL), proteína associada à hemicelulose (PHEM) e proteína associada à lignina (PLIG)

\begin{tabular}{cccc}
\hline \multirow{2}{*}{ Item } & Silagem de capim-elefante & Silagem de milho & Cana-de-açúcar \\
\cline { 2 - 4 } PIDN & $1,44 \pm 0,027$ & \% da matéria seca \\
PIDA & $1,27 \pm 0,009$ & $1,92 \pm 0,075$ & $1,13 \pm 0,064$ \\
PCEL & $0,63 \pm 0,015$ & $1,46 \pm 0,025$ & $0,77 \pm 0,025$ \\
PHEM & $0,18 \pm 0,020$ & $0,99 \pm 0,045$ & $0,42 \pm 0,017$ \\
PLIG & $0,64 \pm 0,023$ & $0,46 \pm 0,050$ & $0,36 \pm 0,038$ \\
& & $0,47 \pm 0,026$ & $0,35 \pm 0,012$ \\
\hline PIDN & $29,95 \pm 0,377$ & $\%$ da proteína bruta \\
PIDA & $26,30 \pm 0,544$ & $33,23 \pm 1,123$ & $43,62 \pm 0,181$ \\
PCEL & $13,03 \pm 0,650$ & $25,30 \pm 0,303$ & $29,71 \pm 0,566$ \\
PHEM & $3,65 \pm 0,353$ & $17,14 \pm 0,692$ & $16,18 \pm 0,406$ \\
PLIG & $13,27 \pm 0,169$ & $7,93 \pm 0,820$ & $13,91 \pm 0,714$ \\
& & $8,17 \pm 0,470$ & $13,52 \pm 0,404$ \\
PCEL & $43,48 \pm 1,698$ & $\%$ do PIDN & $37,11 \pm 0,952$ \\
PHEM & $12,20 \pm 1,190$ & $51,56 \pm 1,186$ & $31,89 \pm 1,520$ \\
PLIG & $44,33 \pm 1,124$ & $23,75 \pm 1,652$ & $31,01 \pm 1,056$ \\
\hline
\end{tabular}

As proteínas estão ubíquas nos diversos componentes da parede celular das plantas, incluindo enzimas, toxinas e proteínas de formação de estrutura (Iiyana et al., 1993). Ligações éster e éter entre lignina e carboidratos são formadas com participação de enzimas durante a polimerização da lignina, principalmente em forragens que apresentam proteínas de parede ricas em aminoácidos glicina, prolina e hidroxiprolina. Desse modo, a associação entre lignina e proteína é um fator inerente à constituição da planta, e pode ser formada em maior ou menor escala dependendo de características morfogênicas.

O conteúdo de PLIG se mostrou bastante elevado, variando de 44,33 a $24,69 \%$ do PIDN para silagens de capim e milho, respectivamente (Tab. 2). Tanto a silagem de milho quanto a cana-de-açúcar apresentaram conteúdo de PLIG bem próximos ao de PHEM, indicando participação equiparável destes sobre o total de compostos nitrogenados associados à parede celular.

A avaliação dos compostos nitrogenados indegradáveis associados à parede celular é apresentada na Tab. 3. Verificou-se que parte de todos os compostos é potencialmente degradável no rúmen, o que contraria os pressupostos relatados por Sniffen et al. (1992) e Agricultural... (1993), segundo os quais o PIDA não apresentaria disponibilidade ruminal, conceito este obviamente projetado a seus subcomponentes (PCEL e PLIG). Parte de PHEM mostrou-se não degradável, contrariando afirmativas de Sniffen et al. (1992), os quais afirmaram ser tal fração (correspondente à fração B3 dos compostos nitrogenados adotada pelo CNCPS) potencialmente degradável no ambiente ruminal.

De outra forma, verificou-se, em adição à presença de porção potencialmente degradável nas frações PCEL e PLIG, elevada variabilidade entre alimentos $(\mathrm{P}<0,10)$ no tocante à dimensão da porção indegradável (Tab. 4). A adoção de um pressuposto por um sistema nutricional, implica na aceitação deste como lei geral de forma independente da população ou alimento avaliados. $\mathrm{O}$ comportamento relatado na Tab. 4, mais uma vez corrobora falhas sobre a pressuposição do PIDA como representante ou estimador da fração protéica indegradável em forragens tropicais (Detmann et al., 2003; 2004), além de indicar que possíveis correções para que se compense a presença de sua porção potencialmente degradável não sejam válidas em função da variabilidade entre alimentos. Tal afirmativa parece suportar os resultados obtidos por Detmann et al. (2004), que relataram ausência de relação entre PIDA e fração indegradável dos compostos nitrogenados em forragens tropicais. 
Tabela 3. Médias e erros-padrão da média para os teores de proteína não degradável insolúvel em detergente neutro (PIIDN), proteína indegradável insolúvel em detergente ácido (PIIDA), proteína indegradável associada à celulose (PICEL), proteína não indegradável associada à hemicelulose (PIHEM) e proteína indegradável associada à lignina (PILIG)

\begin{tabular}{cccc}
\hline \multirow{2}{*}{ Item } & Silagem capim-elefante $^{1}$ & Silagem de milho $^{1}$ & Cana-de-açúcar $^{1}$ \\
\cline { 2 - 4 } & \multicolumn{3}{c}{ da matéria seca } \\
PIIDN & $1,14 \pm 0,013$ & $1,16 \pm 0,015$ & $0,80 \pm 0,046$ \\
PIIDA & $1,06 \pm 0,002$ & $0,83 \pm 0,009$ & $0,61 \pm 0,009$ \\
PICEL & $0,55 \pm 0,025$ & $0,53 \pm 0,056$ & $0,29 \pm 0,023$ \\
PIHEM & $0,09 \pm 0,012$ & $0,33 \pm 0,020$ & $0,19 \pm 0,038$ \\
PILIG & $0,50 \pm 0,024$ & $0,30 \pm 0,056$ & $0,32 \pm 0,022$ \\
\cline { 2 - 4 } & $23,60 \pm 0,381$ & $\%$ da proteína bruta \\
PIIDN & $21,94 \pm 0,582$ & $20,06 \pm 0,354$ & $30,67 \pm 0,733$ \\
PIIDA & $11,49 \pm 0,610$ & $14,41 \pm 0,192$ & $23,71 \pm 0,877$ \\
PICEL & $1,65 \pm 0,221$ & $9,23 \pm 1,020$ & $11,22 \pm 1,062$ \\
PIHEM & $10,45 \pm 0,544$ & $5,65 \pm 0,366$ & $6,96 \pm 1,112$ \\
PILIG & & $5,18 \pm 0,940$ & $12,49 \pm 0,915$ \\
& & $\%$ do PIDN & $25,72 \pm 2,424$ \\
PICEL & $38,37 \pm 2,116$ & $28,03 \pm 4,014$ & $15,94 \pm 2,486$ \\
PIHEM & $5,54 \pm 0,767$ & $17,07 \pm 1,486$ & $28,64 \pm 2,209$ \\
PILIG & $34,87 \pm 1,448$ & $15,44 \pm 2,442$ &
\end{tabular}

Tabela 4. Médias e coeficientes de variação (CV) para os resíduos indegradáveis (\% da fração) da proteína insolúvel em detergente neutro (PIDN), proteína insolúvel em detergente ácido (PIDA), proteína associada à celulose (PCEL), proteína associada à hemicelulose (PHEM) e proteína associada à lignina (PLIG)

\begin{tabular}{ccccr}
\hline Resíduo & Silagem de capim-elefante & Silagem de milho & Cana-de-açúcar & CV $(\%)$ \\
\hline PIDN & $78,8 \mathrm{~A}$ & $60,5 \mathrm{C}$ & $70,3 \mathrm{~B}$ & 4,9 \\
PIDA & 83,4A & $57,0 \mathrm{C}$ & $79,7 \mathrm{~B}$ & 2,8 \\
PHEM & $45,1 \mathrm{~B}$ & $73,2 \mathrm{~A}$ & $49,6 \mathrm{~B}$ & 22,3 \\
PCEL & $88,4 \mathrm{~A}$ & $54,0 \mathrm{~B}$ & $69,1 \mathrm{~B}$ & 14,4 \\
PLIG & $78,9 \mathrm{AB}$ & $64,0 \mathrm{~B}$ & $92,2 \mathrm{~A}$ & 18,8 \\
\hline
\end{tabular}

Médias na linha seguidas por letras distintas diferem entre si pelo teste DMS Fisher $(\mathrm{P}<0,10)$.

A fração não degradável deve ser considerada, em essência, um conceito biológico, a qual sofre influências diretas e interações entre efeitos químicos, fisiológicos, anatômicos e ambientais, limitando potencialmente o acesso microbiano (Detmann et al., 2004). Estimativas das frações digestíveis ou não digestíveis dos alimentos por intermédio do resíduo em detergente ácido não se mostram biologicamente válidas (Van Soest, 1994). Dessa forma, a aproximação da fração indegradável dos compostos nitrogenados por intermédio do PIDA consistiria em mera aproximação química, resultando em vícios e erros substanciais sobre as estimativas obtidas. Neste contexto, estimativas verossímeis desta fração somente poderiam ser obtidas via métodos biológicos, como via proteína indegradável insolúvel em detergente neutro (PIIDN) (Detmann et al., 2004)

Observa-se que porção significativa da lignina é constituída por compostos nitrogenados (Tab. 5). A consideração dessa fração contaminante reduziu, em média, em $6,0 \%$ os teores de lignina nos alimentos avaliados. Embora o prétratamento da amostra com detergente ácido tenha por principal objetivo a redução de interferências atribuídas aos compostos nitrogenados na avaliação dos teores de lignina dos alimentos (Van Soest, 1994), verifica-se ainda contribuição substancial desses compostos sobre a estimativa final da concentração de lignina. 
Tabela 5. Médias e erros-padrão da média para os teores de lignina (\% da MS), lignina corrigida para conteúdo de proteína (LIGp - \% da MS) e proteína associada à lignina (PLIG - \% da lignina)

\begin{tabular}{cccc}
\hline Item & Silagem de capim-elefante & Silagem de milho & Cana-de-açúcar \\
\hline Lignina & $10,25 \pm 0,103$ & $8,48 \pm 2,458$ & $5,42 \pm 0,125$ \\
LIGp & $9,61 \pm 0,097$ & $8,01 \pm 2,407$ & $5,07 \pm 0,117$ \\
PLIG & $6,24 \pm 0,224$ & $5,54 \pm 0,306$ & $6,46 \pm 0,221$ \\
\hline
\end{tabular}

A interferência dos compostos nitrogenados foi relatada por Reevers (1997) como o problema mais comum na quantificação dos teores de lignina. Dessa forma, sugere-se que a correção em relação à PLIG possa implicar estimativas mais verossímeis dos teores de lignina presentes nos alimentos.

Um dos principais limitantes à estimação da fração indegradável dos componentes fibrosos (FDNi) dos alimentos tropicais a partir de sua composição química reside sobre a baixa correlação entre esta fração e os compostos fenólicos da parede celular. Sendo a ação dos compostos nitrogenados não-deletéria sobre a atuação da população microbiana ruminal, a consideração dos teores de lignina corrigidos para compostos nitrogenados (LIGp) poderia auxiliar no incremento das correlações entre FDNi e lignina, uma vez que esta última, caso corrigida, concentraria com maior intensidade os componentes com efeitos deletérios sobre a degradação ruminal dos carboidratos fibrosos.

Palavras-chave: degradação ruminal, lignina, proteína insolúvel em detergente ácido, proteína insolúvel em detergente neutro.

\begin{abstract}
The total and undegradable fractions of nitrogenous compounds associated to cell wall organic matrix in some tropical forages were evaluated. Samples of corn silage, elephantgrass silage and sugarcane were used. Neutral detergent insoluble nitrogenous compounds were divided in three different fractions associated with: hemicellulose (HN), cellulose $(C N)$, and lignin $(L N)$. The size of the different fractions varied among feeds. A portion of acid detergent insoluble nitrogen, which is the sum of CN and LN, was potentially degradable in the rumen. A portion of $H N$ was not degradable in the rumen. The heterogeneous dimensions of degradable portion of all nitrogenous compounds among feeds can compromise the estimates of cell wall undegradable nitrogen by simple chemical approaches in tropical forages. The LN overestimated the lignin contents and the correction for those compounds on lignin has been suggested.
\end{abstract}

Keywords: rumen, degradability, lignin, insoluble protein

\section{REFERÊNCIAS BIBLIOGRÁFICAS}

AGRICULTURAL and Food Research Council. Energy and protein requirements of ruminants. Wallingford: CAB International, 1993. 159p.

CABRAL, L.S.; VALADARES FILHO, S.C.; MALAFAIA, P.A.M. et al. Frações protéicas de alimentos tropicais e suas taxas de digestão estimadas pela incubação com proteases ruminais. Rev. Bras. Zootec., v.29, p.2316-2324, 2000.

CASALI, A.; DETMANN, E.; CARLI, V. et al. Estimação in situ dos teores de fibra em detergente neutro indigestível em alimentos para ruminantes em sacos de diferentes tecidos In: MOSTRA CIENTÍFICA DE PÓSGRADUAÇÃO, 5., 2005, Viçosa. Anais... Viçosa: UFV (CD-ROM).

DETMANN, E.; CLIPES, R.C.; SILVA, J.F.C. et al. Avaliação da proteína insolúvel em detergente ácido como estimador da fração protéica indegradável no rúmen em forragens tropicais. In: REUNIÃO ANUAL DA SOCIEDADE BRASILEIRA DE ZOOTECNIA, 41., 2004, Campo Grande. Anais... Campo Grande: Sociedade Brasileira de Zootecnia, 2004. (CD-ROM). 
DETMANN, E.; PAULINO, M.F.; ZERVOUDAKIS, J.T. et al. Evaluation of digestibility of acid detergent insoluble nitrogen in cattle grazing a signal grass pasture. In: WORLD CONFERENCE OF ANIMAL PRODUCTION, 9., 2003, Porto Alegre. Proceedings... Porto Alegre: World Association for Animal Production, 2003 (CD-ROM).

LLYAMA, K.; LAM, T.B.T.; MEIKLE, P.J. et al. Cell wall biosynthesis and its regulation. In: JUNG, H.G.; BUXTON, D.R.; HATFIELD, R.D. et al. (Ed.). Forage cell wall structure and digestibility. Madison: American Society of Agronomy, 1993. p. 621-684.

LICITRA, G.; HERNANDEZ, T.M.; VAN SOEST, P.J. Standardization of procedures for nitrogen fractionation of ruminant feeds. Anim. Feed Sci. Technol., v.57, p.347-358, 1996.
OFFICIAL methods of analysis. 15.ed. Arlington: AOAC International, 1990. 1117p.

REEVERS, J.B. Relationship between crude protein and determination of nondispersible lignin. J. Dairy Sci., v.80, p.692-699, 1997.

SNIFFEN, C.J.; O'CONNOR, J.D.; VAN SOEST, P.J. et al. A net carbohydrate and protein system for evaluating cattle diets: II. Carbohydrate and protein availability. J. Anim. Sci., v.70, p.3562-3577, 1992.

VAN SOEST, P.J. Nutritional ecology of the ruminant. 2.ed. Ithaca: Cornell University, 1994. 476p.

VAN SOEST, P.J.; ROBERTSON, J.B. Analysis of forages and fibrous foods. Ithaca: Cornell University, 1985. 202p. 